\title{
Buscando uma interação teatral poética e dialógica com comunidades
}

\section{Marcia Pompeo Nogueira}

Universidade do Estado de Santa Catarina

A prática de interação com comunidades através do teatro não é nova, entretanto pude constatar que ela vem acontecendo com mais freqüência em outros países do chamado terceiro mundo do que no Brasil. O que é mais surpreendente é que a principal fundamentação teórica destas práticas é baseada no trabalho de dois brasileiros: Paulo Freire e Augusto Boal.

Os trabalhos que pude pesquisar no meu doutorado', através de pesquisa de campo e bibliográfica, enquadram-se na abordagem dialógica do teatro para o desenvolvimento. Eles visam ao fortalecimento de comunidades, contribuindo enquanto um meio de comunicação entre diferentes setores da comunidade e enquanto forma de identificação e solução de problemas.

Trata-se de um teatro que envolve a comunidade em todo o processo teatral, incluindo a criação do texto e representação que são baseadas em problemas apontados pelos participantes. O método de abordagem das comunidades é baseado no respeito ao conhecimento e às formas de expressão da cultura local. Este método foi sendo desenvolvido e aprimorado através de intercâmbios entre facilitadores que tomaram parte em oficinas e conferência internacionais muito freqüentes nos anos oitenta principalmente no continente Africano. Estes encontros envolviam discussões e prática teatral em uma comunidade local.

Para sistematizar o método dialógico de teatro para o desenvolvimento, decidi focar, entre diversas fontes bibliográficas, em dois workshops que aconteceram na África nos anos 80, um no Zimbabwe, outro na Nigéria. Ambos são fundamentados nos princípios educacionais de Paulo Freire, e são profundamente influenciados por Augusto Boal. O processo de interação com a comunidade, segundo este método, envolve cinco etapas, desde a identificação do problema até a apresentação final:

\footnotetext{
${ }^{1}$ Doutorado feito na Universidade de Exeter e concluído em junho de 2002.
} 


\section{Preparação para a interação com a comunidade}

Inicialmente, o grupo contata a comunidade, pedindo autorização para o trabalho acontecer. Em seguida, o grupo de facilitadores cria um repertório comum, antes de ir para a prática. Seu papel deixa de ser o do especialista, do profissional que vem com um projeto pronto, e passa a ser o de alguém que vai coordenar um processo aberto para as contribuições dos membros da comunidade. $\mathrm{O}$ facilitador faz perguntas no lugar de dar respostas. Encoraja membros da comunidade para por suas idéias em prática. Ajuda a manter o foco no problema como forma de ajudar na sua solução. Abre espaço para diferentes setores da comunidade para apresentar seus pontos de vista. Garante a democracia dentro do processo.

\section{Identificação do conteúdo}

No primeiro momento na comunidade, a atenção está voltada para conhecer as pessoas e se inteirar do que acontece lá. Trata-se de uma aprendizagem gradual. No workshop do Zimbabwe os facilitadores se prepararam para atuar da seguinte maneira:

- Dando informações e consultado as lideranças locais;

- Adotando as formas locais de cumprimento;

- Apresentando-se, falando de sua experiência, assim o processo de conhecimento é duplo, e não um interrogatório deles;

- Explicando sua proposta e a natureza do trabalho que se pretendia desenvolver, de forma que entendessem porque este grupo de fora estava lá e para motivá-los a participar;

- Falando com as pessoas numa situação de igualdade e mostrando interesse genuíno no que eles diziam;

- Batendo papo informalmente e não entrevistando formalmente;

- Encorajando a troca de músicas, danças para se criar uma relação de participação;

- Descobrindo qual é a experiência da comunidade;

- Sendo consciente da presença deles lá;

- Sabendo que os dois lados aprendem com a experiência (Kidd 1984:18).

Os facilitadores se dividiram em pares que passearam pela comunidade, 
conversando com as pessoas, visitando as instituições e convidando as pessoas para uma reunião. Isto permitiu um contato não apenas com as pessoas mais articuladas, o que ajudou a formar uma visão mais abrangente da comunidade.

\section{Reunião com as pessoas da comunidade}

As reuniões geralmente se iniciam com troca de músicas e danças entre os facilitadores e as pessoas da comunidade. Isto representa um reconhecimento de que ambos possuem cultura e conhecimento, ajuda a quebrar as barreiras entre os dois lados, e representa um novo meio de conhecer um ao outro. Este processo é descrito da seguinte forma por Steve Oga Abah: A tradição de narrativas orais, músicas e danças são formas comunitárias que enfatizam e realmente revelam a ética e os costumes da vida na comunidade e sua orientação coletiva na forma que lidam com os assuntos da comunidade. Os animadores viram e se identificaram com esta abordagem. O grupo trocou músicas, dançou, e sentaram para beber e comer com as pessoas da comunidade. Dessa forma, os animadores quebraram barreiras e se integraram com a comunidade. Isto abriu caminho para uma pesquisa efetiva com a comunidade (Abah, 1997: 33).

Depois de algum tempo compartilhando músicas, os facilitadores explicam a proposta de trabalho. Durante o workshop no Zimbabwe, os facilitadores apresentaram os objetivos e em seguida dividiram a comunidade em grupos para identificar os problemas que a comunidade queria entender e buscar soluções.

O passo seguinte é o isolamento de um problema maior. Como não é possível endereçar toda a informação adquirida no campo e na discussão, é importante selecionar a principal preocupação para servir de base para o processo teatral. É requerido das pessoas da comunidade que selecionem o problema que mais os aflige.

O facilitador coordena o processo de decisão, ajudando a manter o foco e garantindo a democracia nos processos de decisão.No final das discussões em grupo, todos se juntam novamente, comentando aspectos da discussão em grupo, organizando a continuidade das atividades, e terminando novamente com uma nova troca de músicas. 


\section{Dramatizando os problemas}

A dramatização é proposta enquanto um processo de aprendizagem acessível a qualquer grupo. Permite uma combinação de análise e dramatização que pode ajudar a tornar certas discussões mais concretas. Improvisando, criando imagens, assumindo papéis permite um olhar diferente sobre a realidade. Enquanto se faz e refaz uma dramatização, os participantes podem focar em detalhes, prestar atenção em diferentes lados das relações. A dramatização também pode ajudar a identificar as causas subjacentes dos problemas, e as razões delas permanecem sem solução. Permite também que diferentes estratégias de solução sejam tentadas. A apresentação dos problemas num palco ajuda a deixá-los mais concretos, o que pode ajudar na organização da comunidade para solucioná-lo. O fato de que todos estes problemas são encaminhados pelas pessoas envolvidas ajuda a dar confiança, a fortalecer o grupo, a aumentar a auto-estima dos participantes. Os moradores da comunidade controlam o processo como um todo.

Existem diferentes abordagens em relação ao uso do teatro como parte deste processo, mas as influências das técnicas de Augusto Boal são marcantes, em especial as do teatro fórum.

\section{Continuidade depois do workshop (follow up)}

A abordagem dialógica do teatro para o desenvolvimento objetiva que o processo seja sustentável pelos moradores da comunidade, sempre enfatizando a autoria do processo. Entretanto, isto não é atingido facilmente. Anos de dominação não podem ser transformados do dia para noite. Depois do workshop a comunidade enfrenta a realidade novamente e não é sempre possível por em prática as alternativas imaginadas no workshop. Em vista disto, é fundamental a continuidade da interação com a comunidade depois do workshop.

O retorno à comunidade é fundamental para a criação de mudanças que possam perpetuar na comunidade, bem como a vinculação do projeto teatral com outros projetos e organizações que atuam na comunidade.

\section{$O$ contexto do trabalho de Ratones}

A abordagem dialógica trouxe muitas contribuições em termos de métodos de interação com comunidades oprimidas, contribuindo para fortalecer 
comunidades. Entretanto, olhando sob outro ponto de vista, não estaria o teatro dialógico assumindo uma forma muito discursiva?

Para discutir esta questão, gostaria de apresentar, enquanto paralelo, uma prática teatral que desenvolvi na comunidade de Ratones, sul do Brasil. Observar as semelhanças e as diferenças entre as duas práticas é parte de uma avaliação pessoal necessária para a definição de meu trabalho futuro, mas que espero possa também trazer novas idéias para a prática na área.

Nosso teatro em comunidade surgiu como resposta a um grupo de jovens de Ratones que veio para a universidade para fazer uma apresentação teatral. Ficamos encantados pela vitalidade e coragem do grupo de se apresentar por conta própria para uma audiência universitária, mas chocados pelo fato de que a apresentação se limitava a cópias de programas humorísticos da televisão. Em conjunto com um grupo de alunos da universidade, fizemos um projeto para trabalhar com este grupo, objetivando a facilitação de uma prática teatral baseada em histórias próximas da realidade e cultura da comunidade. Esta prática se tornou, entre 1991 e 1998, um campo de estágio para diversos alunos da Universidade do Estado de Santa Catarina e, para mim, um campo de trabalho que me energizou e me ensinou muitíssimo.

Ratones é uma pequena comunidade que fica no interior da ilha de Santa Catarina, em Florianópolis. Até uns cinqüenta anos atrás, era uma comunidade rural, auto-suficiente, que tinha uma clara identidade cultural. Neste tempo, para ir à ao centro de Florianópolis se tomava um dia inteiro. Não existiam escolas em Ratones. Hoje, a produção agrícola sofre duramente com a concorrência da agricultura industrializada e da falta de terras para se plantar, já que a maioria das terras foi vendida, às vezes para se comprar apenas uma geladeira. A maioria dos habitantes deixa a comunidade diariamente para trabalhar na cidade. Ratones está hoje conectada ao centro de Florianópolis por uma linha regular de ônibus. Existe uma escola municipal de primeiro grau, local onde nosso trabalho costumava acontecer, muitas igrejas, lojinhas e bares. A identidade cultural se enfraqueceu.

O grupo de jovens com quem trabalhamos costumava reclamar que: 'nada acontece em Ratones!' Talvez por causa disto nós tenhamos conseguido manter o trabalho de teatro por oito anos, sempre com um alto nível de energia e comprometimento dos adolescentes que costumavam esperar ansiosamente pelo nosso workshop semanal, mesmo que nossos encontros acontecessem na hora das novelas mais populares da televisão. 
Nosso grupo, Sonho de Criança, era formado por cerca de trinta pessoas com idades variando entre quatro e vinte anos. Juntos criamos três peças que resultaram de processos longos de um ano e meio cada, incluindo as apresentações.

País dos Urubus² foi criada em 1991 como parte de nosso processo de conhecer o grupo e a comunidade. Depois de trocarmos músicas e danças de roda, pedimos a eles que desenhassem os caminhos da comunidade, e para nos contarem histórias de mentira e de verdade que aconteceram nestes caminhos ${ }^{3}$. Entre as imagens que desenharam e as histórias que contaram, escolhemos a imagem do País dos Urubus para ser desenvolvida em nosso processo teatral. A imagem surgiu como uma história de mentira identificada como parte dos caminhos de Ratones. Para mim, e para o grupo de universitários que tomaram parte do projeto, esta imagem foi selecionada por seu potencial simbólico. Para o grupo de adolescentes, era divertido imaginar um país de urubus. Como era este país? Quem teria poder nele? Como era a vida das pessoas que lá viviam?

O país criado era muito corrupto. O objetivo do ministro da educação era: "ensinar as crianças a não tomar banho, a falar palavrões, a fazer grafite, a preservar a sujeira, a poluir, não limpar os banheiros deixando sempre aquele cheirinho gostoso...”. A principal contradição deste país era que, apesar de sua cultura poluidora, os urubus necessitavam água bem limpa para beber. Para garantir que os representantes do poder tivessem estoque de carniça suficiente, costumavam raptar a prender os idosos. A peça se desenvolveu em torno da história de uma criança com poderes mágicos, que tentava salvar seus avós de serem capturados e presos pela polícia, de forma a virar comida da elite de urubus.

A segunda peça criada coletivamente foi História do Não Sei. Não Sei era um personagem que emergiu em um workshop e nos impressionou por suas possibilidades simbólicas. Para desenvolver o significado deste personagem,

${ }^{2}$ Sobre o processo de criação de País dos Urubus ver Nogueira, M.P. "Teatro na Educação: uma Proposta de Superação da Dicotomia entre Processo e Produto".

3 Esta proposta de desenho dos caminhos da comunidade é parte do método de trabalho de Ili Krugli, veja Nogueira, 1993.

4 Do texo 'País dos Urubus'. Criado a partir da gravação de apresentações improvisadas.

${ }^{5}$ Ver Nogueira, M.P. 'Community Theatre in Florianópolis'. 
organizamos workshops em três diferentes comunidades ${ }^{\varsigma}$. Pedimos aos participantes que dessem forma ao Não Sei usando folhas de jornal, e para desenvolver seu mapa da vida , feito a partir de desenhos da vida do personagem antes de nascer, seu presente - incluindo seus sonhos - e seu futuro. Muitos aspectos deste personagem vieram à tona. Para alguns, ser Não Sei significava não saber quem eram seus pais, não saber o que a escola queria que eles soubessem, apesar de saberem que aqueles que sabem exploram os que não sabem. A forma dada ao Não Sei, pelo grupo de Ratones, era um boneco que tinha seios, rabo e pênis, Não Sei não sabia se era um menino ou uma menina.

A história criada unia as dúvidas das crianças das três comunidades, mas como somente a comunidade de Ratones criou o espetáculo, focamos a história do Não Sei na questão de gênero, numa tentativa de responder às necessidades expressas pela criação do boneco andrógino.

Na história criada, nosso personagem pesquisou sua identidade na comunidade em que foi adotado(a), já que não sabia quem eram seus pais. A revelação surgiu através de uma viagem pra dentro de seu corpo, quando Não Sei descobriu que era homem. Após esta descoberta, decidiu enterrar seu lado feminino, do qual nasceu uma árvore. O fruto dessa árvore foi transformado numa mulher de quem Não Sei se apaixonou.

Esta história cresceu passo a passo durante nossos workshops com o grupo de Ratones, que era na sua maioria composto por participantes de doze anos. Todas as soluções encontradas para o desenvolvimento da história vieram do grupo; nosso método de criação tinha como base responder às perguntas dos

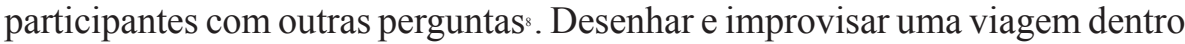
do corpo foi inicialmente desenvolvido enquanto uma busca pessoal feita por todos os participantes. $\mathrm{O}$ segundo passo foi imaginar nosso personagem fazendo a mesma pesquisa em seu corpo. Que órgãos ele pode encontrar?

Esta atividade aumentou o entendimento a respeito do processo de

\footnotetext{
6 As três comunidades eram: Morro do Mocotó, uma favela próxima do centro de Florianópolis formada em sua maioria por moradores negros; Coloninha, uma comunidade mais recente feita de pessoas que vieram para capital fugindo do campo por causa dos efeitos da mecanização do campo; e Ratones.

${ }^{7}$ O Mapa da vida é uma atividade que integra o método de Ilo Krugli. Ilo Krugli é um diretor teatral que influenciou profundamente meu trabalho. Seu trabalho foi o foco de minha dissertação de mestrado: Teatro com Meninos de Rua. Este mestrado foi concluído na Escola de Comunicações e Artes da USP.
} 
mudança vivido no corpo dos jovens com quem trabalhávamos. Improvisando brincadeiras de meninas, e brincadeiras de meninos; improvisando cenas em que uma mãe dá conselhos para uma filha, e um pai dá conselhos para um filho ajudou o grupo a identificar a diferença na expectativa cultural em relação à educação sexual de meninos e meninas de sua comunidade.

Foi um processo teatral que permitiu ao grupo investigar questões íntimas muito profundas. A peça foi apresentada para diferentes comunidades, incluindo as outras comunidades que tomaram parte na pesquisa sobre o personagem Não Sei. Entretanto, o grupo decidiu não se apresentar em sua comunidade. O conteúdo era pessoal demais, eles não quiseram compartilhá-lo com seus familiares. Entretanto, durante a seleção do tema de nosso próximo espetáculo, o grupo tinha certeza de que dessa vez queriam criar uma peça para a comunidade de Ratones.

O tema de nossa terceira peça A Outra História do Boi ${ }^{\circ}$ era relacionado com uma manifestação cultural que acontece de norte a sul no Brasil, sobre a morte e ressurreição de um boi. Em Florianópolis esta manifestação se chama Boi de Mamão. Ela é brincada na maioria dos bairros de Florianópolis, mas não em Ratones. Isto nos intrigou: por que esta manifestação cultural não era mais viva em Ratones que, por causa de sua localização no interior da Ilha de Santa Catarina, é mais preservada da invasão turística do que outras comunidades de Florianópolis? Enquanto o coordenador de dança e música do projeto, Reonaldo Gonçalves, entrevistava informalmente pessoas da comunidade, ouviu que eles pararam de brincar o Boi de Mamão depois do assassinato, durante uma apresentação, do homem que dançava o boi. Esta informação virou o tema central de nosso processo teatral. Descobrimos que o assassinato, o qual não tínhamos certeza de que tenha realmente acontecido, era uma representação simbólica da morte da identidade cultural da comunidade.

O processo teatral começou com a criação de uma comunidade fictícia onde este assassinato aconteceu. Organizados em torno de famílias, cada participante foi requisitado a criar o seu personagem baseado em pessoas que eles conhecessem do passado e presente de Ratones. A escolha de integrar pessoas

\footnotetext{
${ }^{8}$ Este método foi influenciado pelo método de Catherine Dasté, que criava históriaspara serem encenadas por seu grupo profissional de teatro infantil, a partir de uma interação com grupos de crianças. Veja Dasté, C.; Jenger, Y.; Voluzan, J. El Niño, el teatro y la Escuela, Madrid: Villalar, 1978.

${ }^{9}$ Veja Nogueira, m. p. 'Theatre and Cultural Renewal'.
} 
reais na criação de uma comunidade fictícia proporcionou ao mesmo tempo proximidade e distância em relação à sua própria comunidade: era como se os participantes estivessem criando "sem querer" a história de suas próprias famílias, de sua comunidade.

A história criada era sobre uma rivalidade entre duas famílias em relação à posse da terra. Ambas foram chamadas pra resolver uma praga que estava matando o gado da região. Espantosamente, apesar da doença estar se generalizando, um boi estava crescendo mais e mais. Um médico foi chamado sem sucesso, uma feiticeira foi então chamada ${ }^{10}$ e descobre que o boi encantado estava grávido e o ajudaramm a dar luz. O bezerro recém-nascido se transformou no boi da brincadeira e ajudou a unir a comunidade. A peça terminava com o Boi de Mamão dançado na forma como era realmente feito na comunidade trinta anos atrás, contando inclusive com a presença dos músicos que animavam o boi naquela época.

A peça foi extremamente bem recebida pela comunidade e para a maioria dos membros do grupo este foi o nosso melhor trabalho.

\section{O conceito de codificação}

Quais seriam as semelhanças e diferenças entre o método dialógico e o desenvolvido em Ratones? Para responder a esta questão, escolhi olhar para ambas as práticas usando como lentes o conceito Freireano de codificação. Acredito que, examinando como as duas práticas se relacionam com os métodos de Paulo Freire, e como ambos os métodos utilizam o conceito de codificação, poderei ter mais dados para a análise dos dois trabalhos e para focar na questão da importância da forma artística num trabalho que objetive uma mudança social. Que tipo de codificação pode ajudar a comunidade a desvelar e a transformar sua realidade? Pode-se trabalhar com codificações imaginárias e mesmo assim manter o foco na realidade da comunidade?

Como parte da educação conscientizadora Freireana, existe um instrumento central proposto para desvelar a realidade, parte do processo de transformar a realidade, o conceito de codificação.

Para Freire, a realidade concreta não pode ser reduzida a fatos observáveis; ela também inclui a forma como a as pessoas a percebem. Subjetividade tem que se unir com objetividade para gerar uma percepção acurada da realidade.

${ }^{10}$ A cena é uma clara re-leitura da cena do médico e da feiticeira no Boi de Mamão. 
Codificação representa uma forma de focar o diálogo - entre os facilitadores e os membros da comunidade envolvidos no projeto - objetivando desvelar a realidade, o que inclui aspectos objetivos e subjetivos. Codificação é feita de situações de vida.

A codificação representa uma dada dimensão da realidade da forma como é vivida pelo povo, esta dimensão é proposta para ser analisada num contexto diferente do que o que ela é vivido. Neste sentido, a codificação transforma o que era uma forma de vida num contexto real, num 'objeto' no contexto teórico (Freire 1972: 32).

Codificação permite aos participantes uma percepção distanciada de sua vida quotidiana, que pode ser admirada, isto é, observada a distância, transformada em um objeto que pode ser coletivamente analisado. A codificação funciona como uma ponte entre os contextos teórico e prático. Uma imagem da realidade concreta é um ponto de partida para uma análise abstrata que pode desvelar profundos relacionamentos dos atores sociais que passam freqüentemente despercebidos. Para Freire, isto faz parte de um processo contínuo de conhecimento onde não se tenta apenas entender a realidade, mas também a percepção anterior que se tinha dela.

Freire apresenta em Pedagogia da Esperança um rico exemplo de codificação que era parte de um projeto educacional que ele visitou em Nova York, onde um grupo de educadores estava trabalhando com Robert Fox:

Numa sala, participantes do grupo, negros e porto-riquenhos. A educadora faz repousar nos braços de uma cadeira a artística foto de uma rua, a mesma em que, dentro de uma de suas casas estávamos e em cuja esquina havia uma quase montanha de lixo.

- O que vemos nesta foto? - perguntou a educadora.

Houve um silêncio como sempre há, não importa onde e a quem façamos a pergunta. Depois, enfático, um deles disse com falsa segurança:

- Vemos aí uma rua da América Latina.

- Mas - disse a educadora - há anúncios em inglês...

Outro silêncio cortado por uma tentativa de ocultar a verdade que doía, que feria, que magoava.

- Ou é uma rua da América Latina e nós fomos lá e ensinamos inglês ou pode ser uma rua da África.

- Por que não Nova York? - perguntou a educadora. 
- Porque somos os Estados Unidos e não podemos ter isso aí. - E, com o dedo indicador apontava a foto.

Depois de um silêncio maior um outro falou e disse, com dificuldade e dor, mas como se tirasse de si um grande peso:

- É preciso reconhecer que esta é a nossa rua. Moramos aqui (Freire 1992: 55-56).

A realidade vivida pelo grupo pode ser melhor percebida através da codificação. A tentativa de esconder a verdade procurando outro lugar para por o lixo é explicada por Freire como expressão da incorporação, pelos educandos, da ideologia dominante que os posiciona como incompetentes e culpados, autores de sua própria desgraça, mas cuja razão de ser é na verdade encontrada na perversidade do sistema (ibid: 56). A codificação contribuiu para a conscientização do grupo de sua realidade e também permitiu o desenvolvimento de uma consciência de sua atitude anterior em relação a esta realidade.

Outro exemplo de codificação é apresentado por Freire em Pedagogia do Oprimido, parte de uma investigação temática em Santiago do Chile. A cena mostrada era de um homem embriagado andando na rua e três jovens conversando numa esquina. Esta cena havia sido proposta para discutir o problema de alcoolismo. Para surpresa do facilitator, os comentários dos educandos foram:

Ai apenas é produtivo e útil à nação o "borracho" que vem voltando para casa, depois do trabalho, em que ganha pouco, preocupado com a família, a cujas necessidades não pode atender. É o único trabalhador. É um trabalhador decente como nós, que também somos "borrachos" (Freire 1977: 133).

Se perguntado diretamente os participantes, poderiam ter afirmado que nunca tinham se embriagado na vida. $\mathrm{O}$ educador poderia ter assumido uma postura moralista contra o alcool sem, entrentanto, levantar uma discussão interessante. Através da codificação o problema de baixos salários, do sentimento de ser incapaz de sustentar a família foram levantados. Ao mesmo tempo, os educandos se reconheceram como " trabalhadores decentes". No lugar de uma discussão moralista, a codificação permitiu que o grupo focasse nas causas do problema. 
A identificação da realidade dos participantes é apenas o começo do trabalho. Freire cita Chonsky em relação ao que se espera da análise da codificação. Ele fala que a 'leitura' da codificação deve incluir o que Chonsky chama de "estruturas de superfície" e as "estruturas profundas" (Freire 1982: 51). O primeiro nível inclui a descrição da codificação, identificando seus elementos constitutivos, que devem ser seguidos de uma exploração mais profunda. Muitos problemas podem ser discutidos a partir de uma codificação.

O processo de descodificação requer que se mova da parte ao todo e que retorne para a parte; do concreto ao abstrato e ao concreto novamente, parte de um constante fluxo e re-fluxo. Através desse processo é possível que se atinja uma perspectiva crítica da realidade concreta, anteriormente percebida como densa e impenetrável (Freire 1977: 114).

A escolha de uma boa codificação é fundamental para o desenvolvimento de uma análise crítica frutífera. Freire apresenta as seguintes condições:

Uma primeira condição a ser cumprida é que, necessariamente, devem representar situações conhecidas pelos indivíduos cuja temática se busca, o que as faz reconheciveis por eles. [...] Igualmente fundamental para sua preparação é a condição de não poderem ter as codificações, de um lado, seu núcleo temático demasiado explícito; de outro, demasiado enigmático. [...] Na medida em que representam situações existenciais, as codificações devem ser simples na sua complexidade e oferecer oportunidades plurais de análise na sua descodificação, o que evita o dirigismo massificador da codificação propagandística. As codificações não são slogans, são objetos cognosciveis, desafios sobre o que deve incidir a reflexão crítica dos sujeitos descodificadores (ibid: 127-128).

\section{$O$ teatro enquanto codificação}

O teatro é um tipo de codificação reconhecido por Freire. Que tipo de teatro poderia preencher os requerimentos de uma codificação frutífera? Seria possível de identificá-la em ambos os métodos, o dialógico e o utilizado em Ratones?

A descrição que Freire faz em relação à pesquisa do universo temático 
na comunidade, a escolha fundamental de uma codificação significativa, é quase idêntica à descrição do método dialógico de Teatro para o Desenvolvimento:

Neste [primeiro] encontro, os investigadores necessitam de obter que um número significativo de pessoas aceite uma conversa informal com eles, em que lhes falarão dos objetivos de sua presença na área. Na qual dirão o porque, o como e o para que da investigação que pretendem realizar e que não podem fazê-lo se não se estabelece uma relação de sim-patia mútuas (ibid: 121).

Ao lado deste trabalho da equipe local, os investigadores iniciam suas visitas à área, sempre autenticamente, nunca forçadamente, como observadores simpáticos. Por isto mesmo, com atitudes compreensivas em face do que observam (ibid: 122).

Na etapa desta igualmente sui generis descodificação, os investigadores, ora incidem sua visão a, observadora, diretamente, sobre certos momentos da existência da área, ora o fazem através de diálogos informais com seus habitantes (ibid: 123).

Os princípios educacionais Freireanos, bem como o método dialógico de teatro para o desenvolvimento, são baseados numa interação com a comunidade alvo. Os facilitadores não decidem o que apresentar às pessoas, nem sugerem um itinerário pré-estabelecido de pesquisa do universo temático da comunidade. Ambos os métodos estão baseados numa abordagem dialógica. Aconteceria o mesmo em Ratones?

Em primeiro lugar, o projeto de teatro de Ratones não foi criado enquanto um fórum para identificar e resolver os problemas da comunidade. $\mathrm{O}$ trabalho em Ratones tinha seu foco na prática teatral a ser desenvolvida por um grupo específico de adolescentes. Entretanto, nós não chegamos em Ratones com uma peça teatral pré-estabelecida. Queríamos pesquisar os interesses do grupo, em torno do que nós criávamos as peças a serem apresentadas pelos adolescentes de Ratones, baseadas em histórias próximas de sua cultura e realidade.

Para criar estas histórias nós também pesquisávamos o contexto da comunidade. A forma com que realizávamos isto era diferente da abordagem dialógica de teatro para o desenvolvimento. Não chegávamos na comunidade fazendo contatos informais com diferentes setores da comunidade. Nós fomos diretamente à escola para pedir permissão para trabalhar lá e para convidar os 
alunos, especialmente aqueles que já faziam parte do grupo de teatro que se apresentou na universidade, para trabalharem conosco. Nós então exploramos o contexto da comunidade através do desenho dos caminhos da comunidade, e através das histórias de mentira e de verdade que aconteceram ali. Entretanto, como este era um projeto de longa duração, nossa imersão na comunidade cresceu de um projeto para o outro. Nós melhoramos o nível de interação com a comunidade durante os oito anos do projeto. A especificidade de nossa abordagem é que, enquanto pesquisávamos o contexto da comunidade, nós não nos preocupávamos apenas com a realidade concreta, mas também com o imaginário que se conectava com esta realidade. Nós procurávamos elementos simbólicos e não apenas idéias racionalmente articuladas.

Meu entendimento de "imaginário" segue Lucian Boia para quem "imaginário" não pode ser definido como algo que acontece fora da realidade concreta. O autor rejeita a dicotomia "real" versus "imaginário".

Imaginário em um sentido se mescla com a realidade, em outro, se confronta com ela. Ele age sobre o mundo e o mundo age sobre ele. Contudo, como parte de sua essência, é feito de uma realidade independente, com sua própria estrutura e sua própria dinâmica. [...] Para levar ao imaginário (pelo menos para sua expressão mais estruturada), a imaginação deve ser fertilizada pela racionalidade. Portanto, o imaginário vai além da representação sensorial. Envolve de um lado imagens percebidas ( e inevitavelmente "adaptadas", porque não existe uma imagem idêntica a um objeto), algumas imagens elaboradas e idéias abstratas estruturando a imagem (Boia 1998: 16-17).

Podemos entender as imagens simbólicas enquanto codificações? O principal requisito para Freire de uma codificação é que apresente situações familiares que possam ser reconhecidas pelos participantes. Mais ainda, a codificação deve favorecer à ampliação do entendimento dos participantes sobre a realidade, que permita a eles construir uma perspectiva mais fiel para explicar a realidade. Seria a discussão sobre fragmentos da realidade o único meio de se atingir isto? Poderia, numa forma similar, uma situação imaginária trazer contribuições que ajudassem a entender a realidade?

Apesar de usar imagens fantásticas, não estávamos, em Ratones, fugindo da realidade. Trabalhávamos com aspectos da realidade da imaginação do grupo, que eram explorados através da exploração das contradições que pudessem ter reflexos no contexto da vida real.

Em País dos Urubus, por exemplo, eles puderam brincar com os conceitos de poder. Criando um país em que a corrupção era a ordem a ser obedecida, puderam encontrar semelhanças com a realidade brasileira. Os elementos fantásticos da narrativa, em um certo sentido, lhes permitiram ver 
o mundo, a eles mesmos, e a sua comunidade com outros olhos, ajudando-os a ir além do ponto de vista dominante.

No espetáculo País dos Urubus nós não propusemos um vínculo concreto entre a corrupção no Brasil e o país imaginário. A proposta era imaginar alguma coisa completamente diferente da realidade, pelo menos da forma ideológica em que a sociedade é apresentada para as crianças. Mas pulado fora de uma abordagem realista, ou da abordagem intelectual de se entender a sociedade, eles encontraram em direção oposta muitos elementos da realidade. O ministro da educação não propôs realmente que se devesse: "preservar a sujeira, poluir, não limpar os banheiros para que fiquem com aquele cheirinho agradável”, mas na escola deles, o banheiro tem sempre um cheiro horrivel. Na peça, os idosos eram raptados e presos para garantir o estoque de carniça. No mundo real, uma manifestação dos aposentados de Florianópolis contrários à aposentadoria miserável que recebiam e lutavam por dignidade. Esta manifestação provocou uma reação: os aposentados apanharam dos policiais e isto apareceu nos noticiários da televisão. Criando suas histórias, as crianças estavam revelando e ampliando seu entendimento sobre a realidade (Nogueira 2000: 114-115).

O trabalho em Ratones estava relacionado com a realidade, mas não era uma simples cópia de aspectos da vida quotidiana. Era uma abordagem poética e lúdica da realidade. Nós estávamos também interessados na exploração de experiências de aprendizagem ricas que eram estruturadas nas nossas reuniões semanais de planejamento.

Nossa escolha da imagem (entre outras criadas pelo grupo) a ser desenvolvida em cada projeto, vinha de nossa bagagem educacional e politica e do conhecimento que tínhamos do grupo e da comunidade em que vivem. Junto com estudantes comprometidos, planejamos passo a passo os conteúdos que poderíamos desenvolver com o grupo. Nossos espetáculos eram o resultado da exploração teatral dos conteúdos que cada tema nos oferecia (ibid: 110-111).

É verdade que nós, algumas vezes, perdemos a oportunidade de estabelecer vínculos concretos entre o mundo fictício e a realidade deles. Era um processo de aprendizagem também para nós! Lentamente aprendemos como 
explorara ricos conteúdos emergentes que se conectavam com nosso processo criativo e lúdico.

No processo criativo de A Outra História do Boi nos baseamos numa história de literatura de cordel chamada $O$ Boi Misterioso. Fazia parte de nosso interesse de beber nas fontes da literatura brasileira para explorar o conteúdo simbólico do boi. A história acontece num período duro de seca. Ao ver seu gado sofrer por falta de pastagem, um fazendeiro desesperado decide abrir as porteiras de sua fazenda, na esperança de que o gado pudesse ter uma melhor sorte em outro lugar. Depois de algum tempo, para surpresa do fazendeiro, um de seus bois volta extremamente gordo e bonito e dá luz a um bezerro. Esta história não termina aí, mas nós decidimos começar nosso trabalho deste fragmento.

A história foi explorada através de improvisação, mas também desenvolvemos algumas atividades para relacioná-la com o contexto de vida dos participantes que vivem uma outra realidade no sul do Brasil. Pedimos a eles que desenhassem como entendiam a atitude do fazendeiro, abrindo as porteiras para os animais que garantiam o seu sustento. Que atitude da vida deles poderia se assemelhar a esta? Nosso conhecimento de Ratones nos ajudava a entender o significado de seus desenhos, e a facilitar debates sobre estes aspectos da realidade deles. Dois desenhos chamaram nossa atenção: um menino tendo que abandonar seu cachorro de estimação, outro uma casa com a placa 'vende-se'. O primeiro exploramos em termos dos sentimentos do fazendeiro, o segundo nos deu oportunidade de discutir a especulação imobiliária em Ratones:

Os facilitadores assumiram papéis e representaram uma cena em que um empresário abordou uma viúva para a persuadir de vender sua terra. Um joker parava a cena em momentos críticos, perguntando aos membros do grupo sobre os pensamentos dos diferentes atores a serem escritos em letreiros de papel.

Nosso foco em História do Não Sei estava na realidade subjetiva do

\footnotetext{
${ }^{11}$ Alguns estudantes de música e teatro do Centro de Artes da Universidade do Estado de Santa Catarina compunham junto comigo o grupo de facilitadores que se encontrava semanalmente para avaliar o trabalho. Mais adiante no processo, alguns jovens de Ratones também tomaram parte nesses encontros.

${ }^{12} \mathrm{O}$ joker (coringa) é proposto por Boal como intermediário que facilita processos de participação dos espectadores nos processos teatrais como o do teatro forum.
} 
grupo. Enquanto explorávamos os 'caminhos de dentro do corpo' e os improvisávamos, a realidade objetiva e as estratégias culturais da educação de gênero eram exploradas, revelando contradições profundas:

Em História do Não Sei o tema era ao mesmo tempo poético e fantástico, um personagem que era meio menina e meio menino. Desenvolvendo-o pudemos nos aprofundar nossa pesquisa sobre a educação sexual e na forma como questões de gênero eram abordadas pela comunidade. Uma cena em que um pai dá conselhos a um filho, e uma mãe dá conselhos a uma filha revelou contradições que os participantes não sabiam. Através de improvisações eles desvelaram as contradições entre a educação de meninos e meninas. As meninas deveriam se preservar de relacionamentos sem futuro, enquanto os meninos deveriam ter relações superficiais para evitar um compromisso muito cedo. Puderam enfrentar contradições como esta durante o processo, desafiando-os a entender a complexidade da educação sexual. Existem alguns depoimentos sobre o significados desta cena na vida deles:

Natanae $l^{13}$ : Você acha que o teatro te ensinou alguma coisa importante para sua vida?

Gabriela: Talvez, quando eu fiz a peça do Não Sei, sobre adolescência, sobre o que as pessoas acham, talvez eu tenha aprendido alguma coisa.

Natanael: Como, que tipo de coisa?

Gabriela: Como as pessoas entendem qual a diferença entre menino e menina, sobre os preconceitos, dos quais nós não tínhamos uma visão mais clara. Eu acho que foi muito interessante (Entrevista pessoal: 11/1998) (ibid: 116).

\section{Formas imaginativas de se criar codificações}

Do meu ponto de vista, as imagens simbólicas escolhidas no centro de cada peça criada em Ratones podem ser identificadas com codificações. Não

\footnotetext{
${ }^{13}$ Natanael e Gabriela são membros do grupo. Esta entrevista fez parte do projeto despedida, antes de eu ir para a Inglaterra para fazer o doutorado, em 1998.
} 
eram aspectos da realidade concreta, $N a ̃ o$ Sei era um personagem fictício, mas exatamente porque era imaginário, ele nos deu uma distância para explorar questões íntimas relacionada com a realidade do grupo.

Olhando criticamente para o nosso trabalho em Ratones, reconheço que nossa análise freqüentemente não atingia o nível das 'estruturas profundas', identificando as causas dos problemas analisados. Em País dos Urubus, por exemplo, permanecemos num nível intuitivo de análise, perdendo algumas pontes concretas entre a intuição do grupo sobre a corrupção no Brasil e o contexto brasileiro real. Em História do Não Sei nossa análise limitou-se ao contexto da comunidade, enquanto parte da exploração do tema. Também falhamos ao não estabelecer vínculos com organizações da comunidade que teriam ampliado o potencial transformativo de nosso trabalho teatral.

Sob outro ponto de vista, o trabalho de Ratones gerou formas imaginativas de se criar uma codificação. Poderia uma representação simbólica da realidade contribuir para o modelo dialógico de teatro para o desenvolvimento? Poderia contribuir para o entendimento da realidade? Elementos fantásticos poderiam contribuir para melhorar nosso entendimento da realidade? Qual o papel da imaginação no processo de compreensão e transformação do mundo?

Como vimos em Freire, uma boa codificação não pode ser nem muito explícita nem muito enigmática. O objetivo não é a propaganda de algum ponto de vista. Entretanto, na abordagem dialógica a codificação teatral é freqüentemente limitada à improvisação de problemas identificados e selecionados pelas pessoas da comunidade. Apesar de usar uma abordagem bastante democrática para dar voz a diferentes setores da comunidade para selecionar uma codificação, a forma de se criar uma codificação é freqüentemente muito explícita, caindo muitas vezes em cenas que não vão além de uma discussão mediada. Seria o conteúdo político de uma peça limitado a seu discurso? Poderia uma forma teatral contribuir para o conteúdo, ou seria ela uma mera distração?

Sob meu ponto de vista, enquanto artistas, podemos levar adiante o conceito de codificação, no sentido de incluir abordagens fantásticas e imaginativas que possam contribuir para aprofundar nosso entendimento da realidade. 


\section{Bibliografia}

ABAH, S. O. 1997. Performing Life: Case Studies in the Practice of Theatre for Development. Zária: Bright Printing Press.

BOAL, A. 1983.Teatro do Oprimido e outras Poéticas Políticas. Rio: Civ. Brasileira. 1996. O Arco-Íris do Desejo: Método Boal de Teatro e Terapia.

Rio: Civ. Brasileira.

BOIA, L. 1998. Pour une Histoire de l'Imaginaire. Paris: Les Belles Lettres.

DASTÉ. C.; JENGER, Y; VOLUZAN, J.,1978.EI Nino, el Teatro y la Escuela. Madrid: Villalar.

FREIRE, P. 1977. Pedagogia do Oprimido. Rio: Paz e Terra, 1977.

1979. Conscientização: Teoria e Prática da Libertação, uma

Introdução ao Pensamento de Paulo Freire. São Paulo: Cortez

$\mathrm{e}$ Moraes.

1981. Criando Métodos de Pesquisa Alternativa: aprendendo a fazê-lo melhor pela Ação. In: Pesquisa Participante. Brandão, C. R. (Ed.). São Paulo: Brasiliense.

1982. Ação Cultural para a Liberdade e outros Escritos. Rio:

Paz e Terra.

Oprimido.

1992. Pedagogia da Esperança: Reencontro com a Pedagogia

d $\mathbf{0}$

KIDD, R. 1984. From People's Theatre for Revolution to Popular

Theatre for Reconstruction: Diary of a Zimbabwean Workshop

The Hague: CESO.

NOGUEIRA, M. P. 1993. Teatro com Meninos de Rua São Paulo: ECA/USP. Tese de Mestrado.

1994. Teatro na Educação: uma proposta de superação da dicotomia entre processo e produto. In O Ensino da Arte em Foco, série Cadernos de ArteEducação, Florianópolis: Deapartamento Artístico Cultural.

1996. Community Theatre in Florianópolis RIDE, Vol. 1, No

1, pp.. 121-128.

Theatre and Cultural Renewal. In Researching in Drama and Theatre in Education: international perspectives, North York: Caput Press (no prelo). 2000. Community Theatre and Change: Reflections on Form and Content. Drama Research, Vol.1, pp. 109-118. 2002. Towards a Poetically Correct Theatre for Development: a Dialogical Approach Exeter: Exeter University. Tese de Doutorado. 